\title{
IMPROVED TERRAIN EFFECTS IN BAROTROPIC FORECASTS
}

\author{
GEORGE P. CRESSMAN \\ Toint Numerical Weather Prediction Unit, U.S. Weather Bureau, Suitland, Md, \\ [Manuccript received September 7, 1960: revised October 4, 1960]
}

\begin{abstract}
The persistent occurrence of systematic errors of barotropic forecasts over mountainous areas is strongly suggestive of significant effects of mountains and friction which have not been included in the previously used forecast models. This study reports on experiments with a new barotropic forecast model which contains an improved mountain effect and a surface friction effect. For computation of the surface stress depending on the wind and on the terrain, a hemispheric map of the drag coefficient is obtained.

The results of tests of the forecast model on an initially zonal flow, and on ten observed meteorological situations, indicate that the effects of terrain on the evolution of atmospheric flow patterns can be of large magnitude, and can account for significant errors in numerical prediction. Some success at accounting for these effects is attained with the barotropic representation of the atmosphere.
\end{abstract}

\section{INTRODUCTION}

In considering the errors of daily barotropic forecasts, one is impressed with the high frequency of occurrence of certain characteristic errors. Some of the most pronounced of these appear with regularity on monthly means of the barotropic errors. One well-known type is associated with frequent cyclogenesis along the east coasts of Asia and North America, and appears as a positive mean algebraic error over these areas during the winter season. Efforts are under way in many research centers to improve our ability to forecast cyclogenesis.

Another frequently observed error is found over western North America, and consists of a tendency to forecast too strong winds in the jet stream as well as a tendency to forecast too low heights of the pressure surfaces. Although it is not clear a priori that these errors are directly topographically induced, since a mountain effect is included in the barotropic forecasts (Cressman [4]), the high dependability of these errors has led us to a reexamination of the orographic influences in the framework of the barotropic forecasts.

Figure 1 is a characteristic monthly error chart showing these errors. The negative error appearing over northwestern Canada and southeastern Alaska appears on practically every monthly error chart, its strength apparently depending on the speed of the westerlies.

\section{RISING AND SINKING OF AIR OVER THE MOUNTAINS}

The customary method of including mountain effects in numerical prediction consists of imagining that the atmosphere extends everywhere to $1000 \mathrm{mb}$., but that a vertical motion is induced at the lower boundary accord- ing to the flow of the fictitious $1000-\mathrm{mb}$. wind up or down the slope of the actual terrain, i.e.

$$
\omega_{0}=\mathrm{V}_{0} \cdot \nabla p_{z}
$$

where $\omega_{0}$ is $d p / d t$ at the lower boundary, $V_{0}$ is the $1000-\mathrm{mb}$. wind, and $p_{g}$ is the standard pressure at the surface of

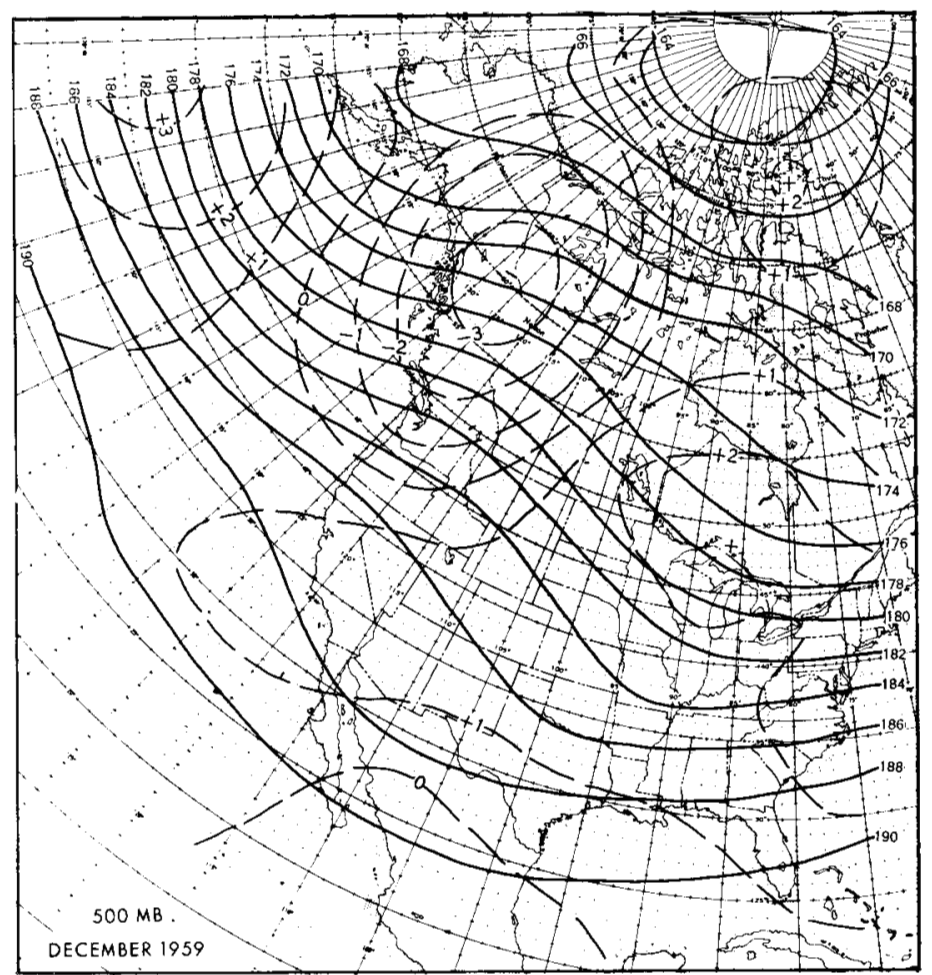

Figcre 1.-Mean 500-mb. chart (solid) and algebraic mean error of 48-hr. 500-mb. forecasts (dashed) for December 1959.

$569382-60 \ldots 5$ 
the ground. The version of this mountain effect used at the Joint Numerical Weather Prediction (JNWP) Unit further supposes that the vertical velocity imposed by this effect falls off from $\omega_{0}$ at $p_{0}(1000 \mathrm{mb}$.) to zero at the pressure $p=0$, giving a $500-\mathrm{mb}$. vorticity tendency due to the mountain effect, $(\partial \zeta / \partial t)_{m}$, of

$$
\left(\frac{\partial \zeta}{\partial t}\right)_{m}=\frac{\eta}{5 p_{0}}\left(\mathrm{~V} \cdot \nabla p_{k}\right)
$$

where $\eta$ is the absolute vorticity at $500 \mathrm{mb}$. and $V$ is the $500-\mathrm{mb}$. wind. It has furthermore been assumed that $\mathrm{V}_{\mathrm{g}}=\mathrm{V} / 5$ since no information exists on winds other than at $500 \mathrm{mb}$. in the barotropic forecast.

The mountain effect represented by equation (2) has proved quite ineflective in practice, giving as a contribution to the 500-mb. height changes only a few decafeet in 24 hours. This mountain effect clearly underestimates the actual atmospheric effect. A more adequate representation of this effect would take account of the lace that at higher elevations than sea level, the vertical velocity decreases upward from the standard pressure at the ground $\left(p_{g}\right)$, and that the wind speed at ground level would be higher than at a fictitious $1000-\mathrm{mb}$. surface. Consequently, in this study an improved mountain efiect is used, namely

$$
\left(\frac{\partial \zeta}{\partial t}\right)_{m}=\left(\frac{\eta}{p_{g}-p_{t}}\right) \mathrm{V}_{g} \cdot \nabla p_{g}
$$

where $p_{t}$ represents the pressure at a mean tropopause, i.e., $200 \mathrm{mb}$., and $V_{g}$ represents the wind at ground level. This is obtained by supposing that $\mathrm{V}_{0}=\mathrm{V} / 5$, and using the interpolation formula

$$
\mathrm{V}_{g}=\mathrm{V}\left[1-0.8\left(\frac{p_{g}-500}{500}\right)\right]
$$

if $p_{g}$ is expressed in millibars.

In making calculations with this mountain effect, the values of $p_{g}$ used were taken from the paper by Berkofsky and Bertoni [3].

\section{INCLUSION OF SURFACE. FRICTION}

The components of the surface stress $\left(\tau_{x}, \tau_{y}\right)$ are related to the ageostrophic mass transport $\left(M_{x}, M_{y}\right)$ by the relations, as given by Holmboe, Forsythe, and Gustin [7], for example,

$$
\begin{aligned}
\tau_{x} & =f M_{y} \\
\tau_{y} & =-f M_{x}
\end{aligned}
$$

If we solve for the mass divergence in the friction layer and introduce the equation of continuity we obtain the wellknown expression for vertical velocity $\omega_{H}$ (actually $(d p / d t)$ at the top of the friction layer,

$$
\omega_{H}=\frac{g}{f}\left(\frac{\partial \tau_{x}}{\partial y}-\frac{\partial \tau_{y}}{\partial x}\right)
$$

Various opinions have been presented regarding the most suitable expression lor the surface stress as a function of the surface geostrophic wind speed. Mintz [12] favors a linear relationship, whereas the data presented by Taylor [22] and by Lettau [9| suggest that the surface stress is more nearly proportional to the square of the wind speed, according to the expression

$$
\tau=C_{d} \rho V_{H}^{2}
$$

where $\rho$ is the density and $C_{d}$ is the skin drag coefficient. We will understand $V_{H}$ as the wind at the top of the friction layer, or the geostrophic surface wind.

Lettau [10] has presented a remarkable analogy between flow in conduits and flow in the atmospheric boundary layer, supporting the use of equation (7), at least for largeseale fiow. In view of the fact that $C_{d}$ varies markedly with changes in the static stability, equation (7) and even the concept of drag coefficient, might not be especially useful for small-scale studies or for forecasts of short time range; e.g., 12 hours. However, since barotropic forecasting is concerned with large-scale atmospheric motions extending over periods of several days, the relation described by equation (7) was selected for use in this study.

In order to incorporate friction into the forecast in any scale of motion smaller than the zonal vortex itself, it is necessary to have a map of the distribution of the drag coefficient over the forecast area, in this case the Northern Hemisphere. Although maps of this type do not appear in the literature, a large number of both empirical and theoretical determinations of surface stress and drag coefficient have been made by various investigators. A number of these will be considered below. In the discussion of numerical values we shall try to discriminate between the drag over flat land or over ocean and the form drag of the large-scale relief of the earth's surface. For this purpose we can consider that the drag coefficient $\dot{C}_{d}$ is made up of two partial drag coefficients, $C_{1}$ and $C_{2}$, where $C_{2}$ will be used to give the form drag of the relief, and $C_{1}$ is relatively constant.

Sawyer [14], following an earlier treatment by Scorer [15], has computed the drag of a mountain ridge by considering the net downward transport of momentum by the gravity oscillations set up in the flow over the ridge. His equation for drag is well suited for computation of numerical values of $C_{2}$. For example, with ridges $300 \mathrm{~m}$. high spaced at $10-\mathrm{km}$. intervals, $C_{2}=0.15 \times 10^{-2}$. This might correspond to the Appalachian Mountains in the eastern United States. Extending the same treatment to extremely rough mountains, $3 \mathrm{~km}$. high, spaced $80 \mathrm{~km}$. apart, we find $C_{2}=0.85 \times 10^{-2}$. This could correspond to the roughest places in the Rocky Mountains or to some areas of Tibet.

It seemed desirable to have for use in this study a relatively simple method for determining the form drag of the mountains, more specifically, $C_{2}$, at a large number of places, having available only the information contained 


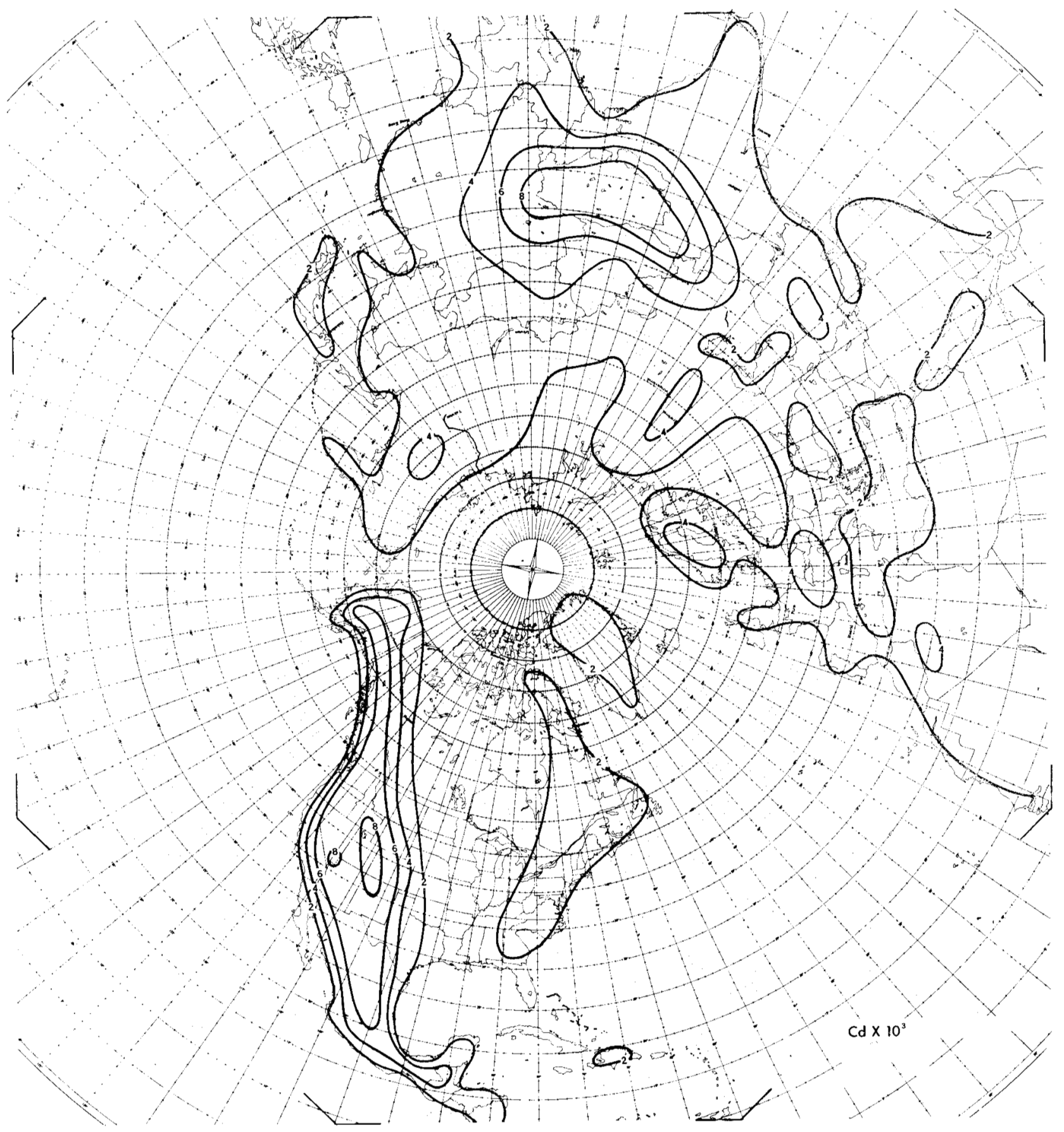

Figure 2.---Hemispheric map of drag coefficient.

in topographical charts. This was done as described in the following paragraph.

The total force exerted on the atmosphere by the mountains, $F$, in a given square of side $d$, can be written as

$$
F=K(n h d)\left(\frac{1}{2} \rho V_{H}^{2}\right)=d^{2} \tau=d^{2} C_{2} \rho V_{H}^{2}
$$

where $n$ is the number of mountain ridges of height $h$ running across a grid square perpendicular to the wind, and $K=E \mathrm{~V}^{2} / V_{I I}^{2}$, where $V$ is considered to be the wind
TABLE 1..Drag coefficient values from wind observations

\begin{tabular}{|c|c|c|}
\hline Worke: & $\underset{\text { coefficient }}{\text { Mrag }}$ & Remarks \\
\hline 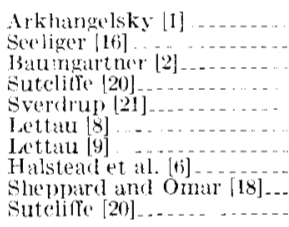 & $\begin{array}{r}4 \times 10^{-3} \\
3 \times 10^{-3} \\
2 \times 10^{-3} \\
1.7 \times 10^{-3} \\
1.5 \times 10^{-3} \\
1.4 \times 10^{-3} \\
1.1 \times 10^{-3} \\
1.1 \times 10^{-3} \\
1.1 \times 10^{-3} \\
0.2 \times 10^{-3}\end{array}$ & $\begin{array}{l}\text { Nountains of moderate height in East Siberia. } \\
\text { Northern Germany. } \\
\text { Nunich Forest. } \\
\text { England (*assume } V_{a} / V_{z}=0.5 \text { ), } \\
\text { Aretie iee. } \\
\text { Leipzig. } \\
\text { O'Veil, Yebr. } \\
\text { College Station, Tex. } \\
\text { Tropical ocean. } \\
\text { North Atlantic (*assume } V_{a} / V_{z}=0.7 \text { ). }\end{array}$ \\
\hline
\end{tabular}

$*_{V_{a}}=$ Wind it anemometer beight, $\gamma_{g}=$ surface geostrophic wind. 
speed at the approximate height $h / 2$ and $E$ is an efficiency number representing the efficiency of the mountains in blocking the flow. In determining the form drag of objects much smaller than mountains, one normally subjects them to a channel or wind tunnel test. Since this was not possible here, it was necessary to estimate $K$ by other means.

In this case empirical data are available from computations of the mass transport of air across surface isobar's. Additionally, several actual measurements of surface stress by drag plates have been made. However, no data are available for very mountainous regions. We will therefore include the calculation from Sawyer's equation for this purpose. Considering that $C_{2}=\dot{C}_{d}-C_{1}$, we obtain from the literature the following values for different types of relicf:

(a) land with trees or with some low relief, $C_{2}=0.1$ to $0.2 \times 10^{-2}$

(b) moderately high mountains, $C_{2}=0.2$ to $0.5 \times 10^{-2}$

(c) very high mountains, $C_{\mathrm{s}}=0.5$ to $0.9 \times 10^{-2}$

A sampling procedure was employed in which values of $n$ and $h$ were determined from detailed acronautical charts at a number of points. From measurements of $n$ and of $h$ (equation (8)) it was observed that a value of $1 / 4$ for $K$ would give approximate agrement with the trpical values of $C_{2}$ eited above. The sampling was then extended, using $K=1 / 4$ until it was possible to sketch a hemispheric map.

In considering the most appropriate value for $C_{1}$, which should apply to very flat land or to oceans, it was found that a widespread agreement exists in the literature, with the exception of baroclinic westerlies over oceans where special problems associated with thermal gradient arise (Sheppard et al. [17]). An average value from the various mass transport calculations gives $C_{1}=0.12 \times 10^{-2}$. The hemispheric map of $C_{d}$, shown in figure 2 , is the result of adding $C_{1}$ to the hemispheric distribution of $C_{2}$ : The selection of independent determinations of drag coefficient is presented in table 1.

Mintz [11] has published a preliminary study in which the surface stress was determined by consideration of the lack of balance between the two sides of a simplified form of the vorticity equation. The values of surface stress which he computed at twelve different locations are about two to five times larger than could be obtained from the drag coefficients reported in table 1. Mintz stated in the same study that he preferred to study possible sources of error before proceeding further. It is hoped that after doing so he will extend his calculations by the novel method he employed.

It is of interest to examine the values of surface stress obtained by various workers investignting the general circulation. From Palmén's [13] value of zonal surlace stress we obtain $C_{t}=0.18 \times 10^{-2}$ by assuming $V_{H}=7 \mathrm{nl}$. sec. ${ }^{-1}$ Palmén obtained his value from calculation of the meridional mass transport, using data from stations at $10^{\circ}$ to $20^{\circ} \mathrm{N}$. Starr and White [19] have given an estimate

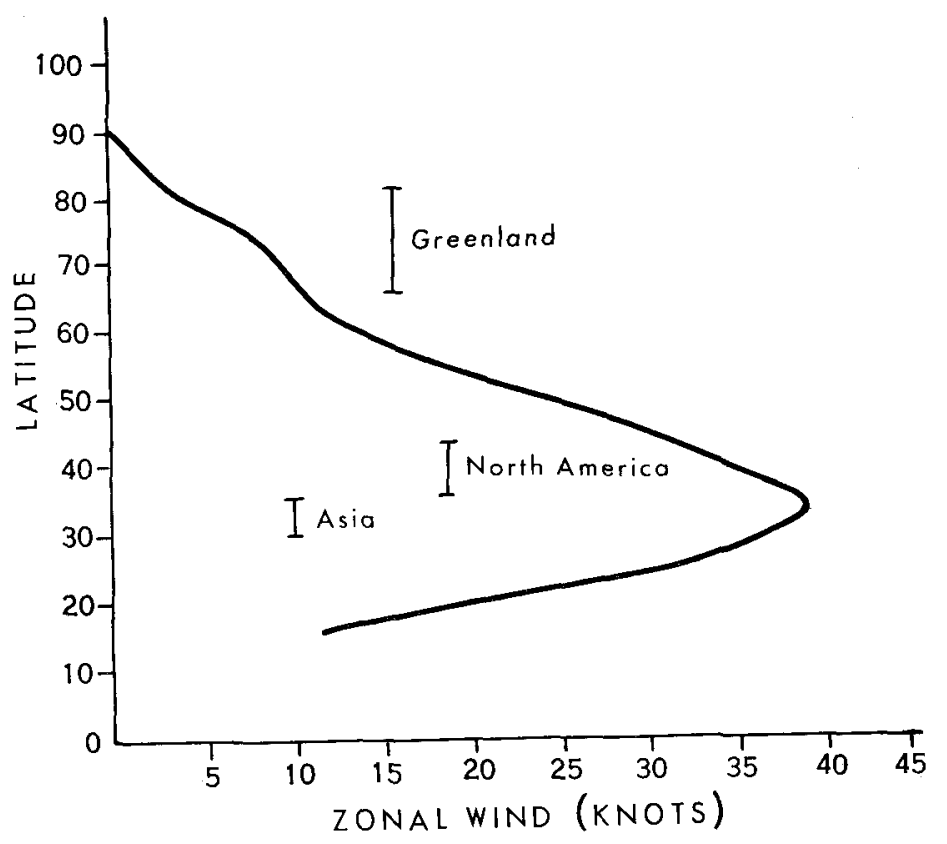

Firiuke 3.-Profile of 500-mb. zonal winds for January. Vertical lines indicate approximate latitudes of highest terrain.

of the normal average diain of angular momentum north of $31^{\circ} \mathrm{N}$., due to surface friction. This can be used to compute an average surface stress over this area by integrating the equation for the torque exerted on a zonal strip of the earth by the atmosphere, with the surface stress assumed constant. Il we further assume an average value of $V_{H}=7 \mathrm{~m}$. sec. ${ }^{-1}$, as in the case of Palmén's data, we obtain an average drag coefficient $C_{d}=0.23 \times 10^{-4}$. These data can be used to check the drag coefficients of figure 2. These values, at the grid points, were weighted by the areas of the grid squares and averaged, giving $C_{t}=0.22 \times 10^{-2}$ for the entire area (Northern Hemisphere north of $15^{\circ} \mathrm{N}$.).

The close agrement between these three válues is partly fortuitous, and cannot be interpreted too literally, due to the approximations made in interpreting the results of Palmén and of Starr and White, particularly in the guess made for $V_{H}$ in each case.

The friction effect is then incorporated into the barotropic forecast in a way similar to the mountain effect (equation, (3)), giving a vorticity change, arising from Priction, $(\partial \zeta / \partial t)_{f}$

$$
\left(\frac{\partial \zeta}{\partial t}\right)_{f}=\frac{\eta \omega_{H}}{p_{g}-p_{t}}
$$

In the calculation of $\omega_{H}$, the lateral variations of $C_{d}$ have been taken into account. The equation suitable for this is obtained from substitution of equation (7) into equation (6), giving the form

$$
\omega_{H}=\frac{\rho g}{f}\left[\frac{\partial}{\partial y}\left(C_{d} u \sqrt{u^{2}+v^{2}}\right)-\frac{\partial}{\partial x}\left(C_{d} v \sqrt{u^{2}+v^{2}}\right)\right]
$$




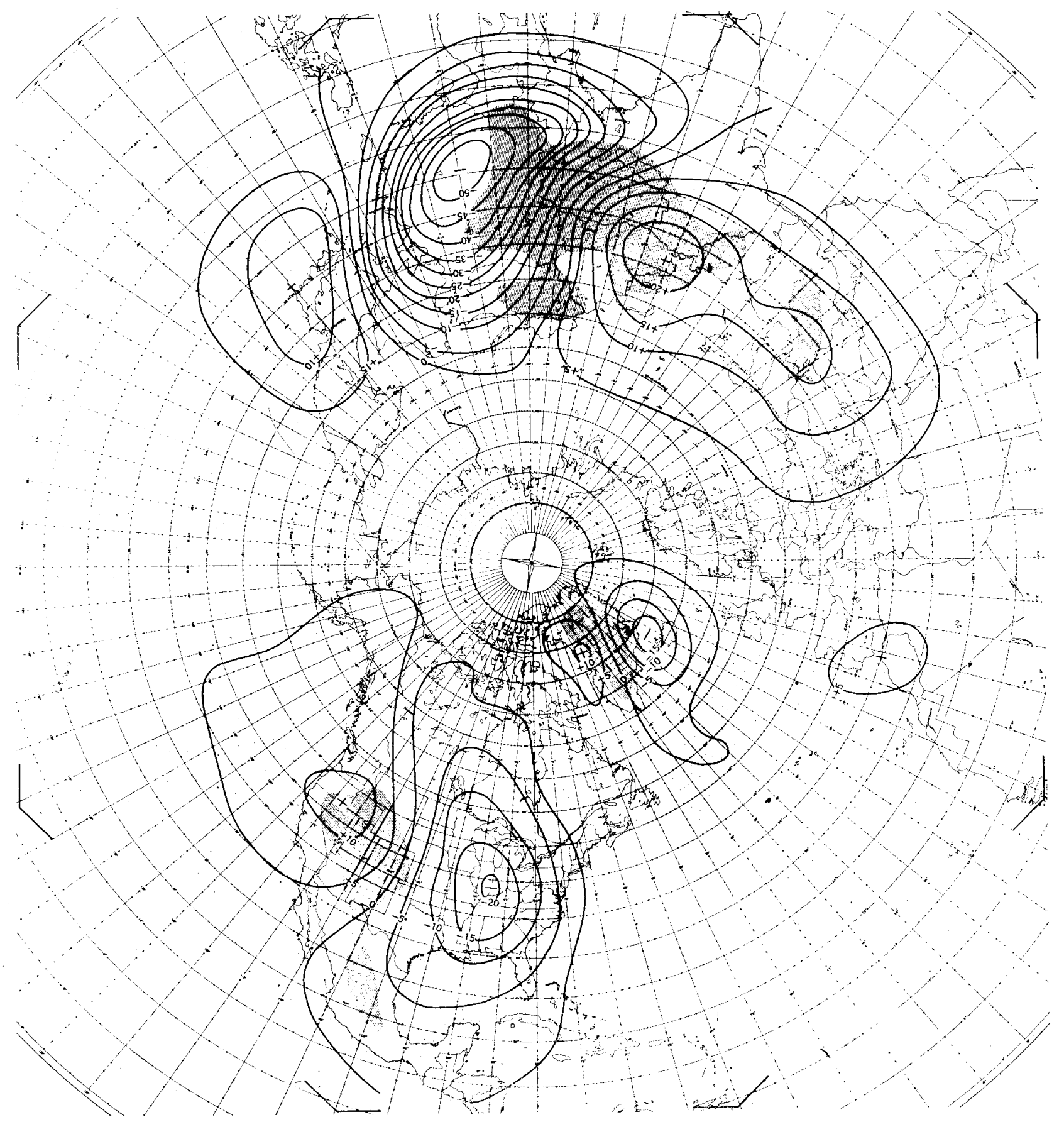

Figure 4.--Deviations (in decafeet) from zonal flow in 48-hr. forecast obtained by including hountain effeet but no friction in forecast model. The highet terrain areas are shaded.

where $u$ and $v$ are the components of $V_{H}$ of equation (7), taken to be the same wind as the $\mathrm{V}_{g}$ of equation (4).

Both mountain and friction effects were then incorporated into the barotropic model described by Cressman [4] in the form

$$
\frac{\partial \zeta}{\partial t}+V \cdot \nabla \eta-\frac{\mu \eta}{\bar{\psi}} \frac{\partial \psi}{\partial t}+\left(\frac{\partial \zeta}{\partial t}\right)_{m}+\left(\frac{\partial \zeta}{\partial t}\right)_{f}=0
$$

where $\psi$ is the stream function. Since the $500-\mathrm{mb}$. wind is represented by a stream function, it would be more correct, strictly speaking, to use a standard value of $f$ as the coefficient of the divergence terms, as shown by Wiin-Niclsen [23]. However, the unbalance of the vorticity budget for the entire area resulting from the use of $\eta$ as a coefficient in the non-friction terms was determined by numerical experiment to be about 1 percent in a 3-day forecast. Consequently, it appears that the form of the coefficient, at least in this model, must be determined by other than vorticity budget-balancing argu- 


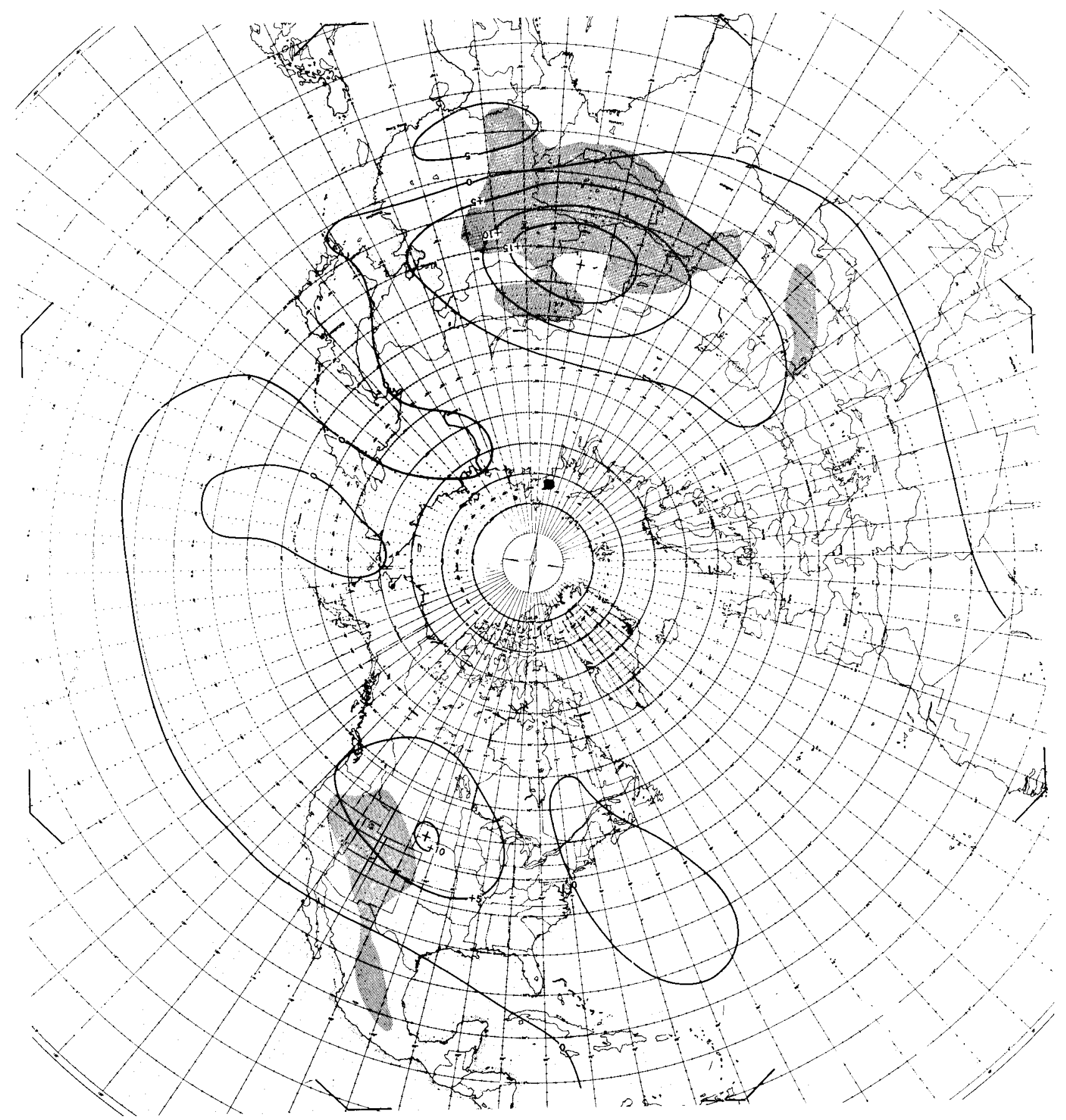

Figtre 5.--Deviations (in decafeet) from zonal flow in 48-hr. forecust obtained by including friction effect but no mountains in forecast model.

ments. No other study of this question was made here, and the question is regarded as unresolved, but probably of small importance.

The computation of the forecasts was made over the 1977-point grid of the Joint Numerical Weather Prediction Unit in 1 -hour time steps. The time required on the IBM 704 for advancing one time step is about 35 seconds without friction and about 55 seconds with friction included, depending to some extent on the time of the rear, since the number of seans required for solution of the Helmboltz equation (11) depends on the vigor of the atmospheric activity.

The time involved in the calculations was shortened by setting $C_{d}$ to zero at all oceanic points. The calculation of $\omega_{H}$ (equation (10)) was then by-passed when all relevant values of $C_{d}$ were found to be zero. Comparison of the 48-hr. forecasts made with and without this extra approximation showed no significant change introduced 


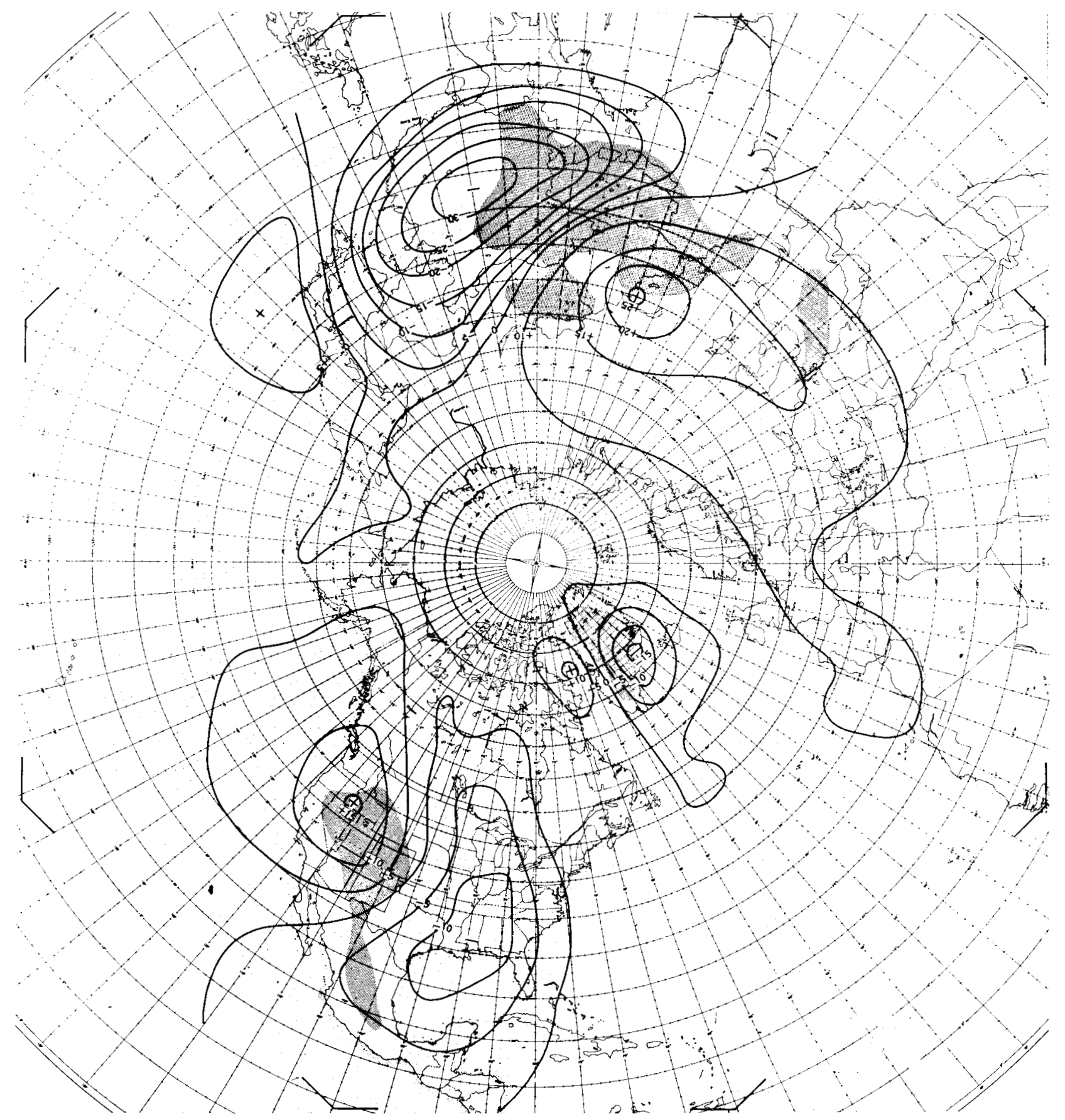

Figure 6,--Deviations (in decafeet) from zonal flow in 48-hr. forcent introduced by combined mountain and friction offects.

by it in either the zonal wind profile or in the local height changes. However, one should be careful not to extend this conclusion for application to more complicated models than the barotropic.

\section{FORECASTS WITH A ZONAL WIND BELT}

In order to obtain an idea of the magnitudes of the mountain and friction effects, a series of barotropic forecasts was made in which the initial data consisted of a set of circular stream lines at $500 \mathrm{mb}$. coincident with the latitude cireles. The zonal profile of the initial data corresponds to the normal hemispheric zonal profile for January, and is shown in figure 3 . This gave an unrealistic distribution of westerlies to the extent that the normal January winds tend to detour around the highest lind masses, particularly in Asia.

For a control, a 72 -hr. forecast was made without either mountains or friction. Any forecast changes would be crroneous, representing the effects of boundary and truncation errors. The maximum change observed in 


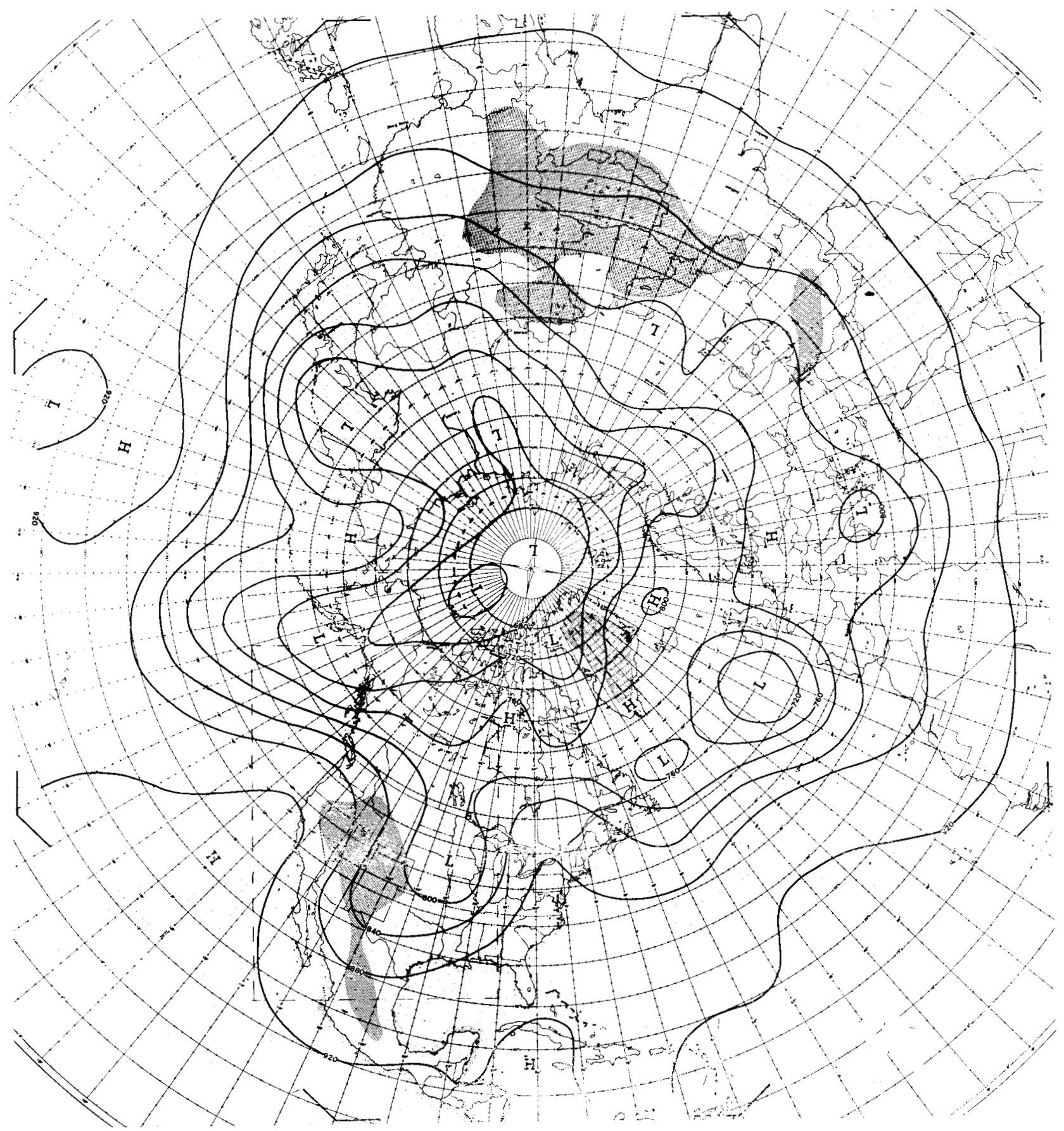

Figure 7.--Initial 500-mb. chart for $1200 \mathrm{GMT}$, April 2, 1960. Dashed line encloses area over which verifications were computed.

this forecast was 20 feet, indicating that the changes introduced into subsequent forecasts by mountain and friction effects were real.

Next, a 48-hr. forecast was made in which the effect of mountains, $(\partial \zeta / \partial t)_{m}$, was included, but in which the effect of friction was excluded. The disturbances which developed on the initially zonal flow are shown in figure 4 . Examination of this figure reveals that the effect of the mountain terms is to turn the flow to the right, with the downwind fall centers having about twice the amplitude of the upwind rise centers.
The result of making a 48-hr. forecast in which the mountain term was excluded and the friction term included is shown in figure 5. The chief impression obtained from this figure is that of a retardation of the zonal flow over the roughest areas of figure 2. Generally speaking, there appears to be a diversion of the fow around the roughest areas.

Figure 6 shows the result of including both mountain and friction terms in the forecast. In this map the fall east of the Asian Plateau is considerably smaller than shown in figure 4 . The formation of a jet stream flowing 


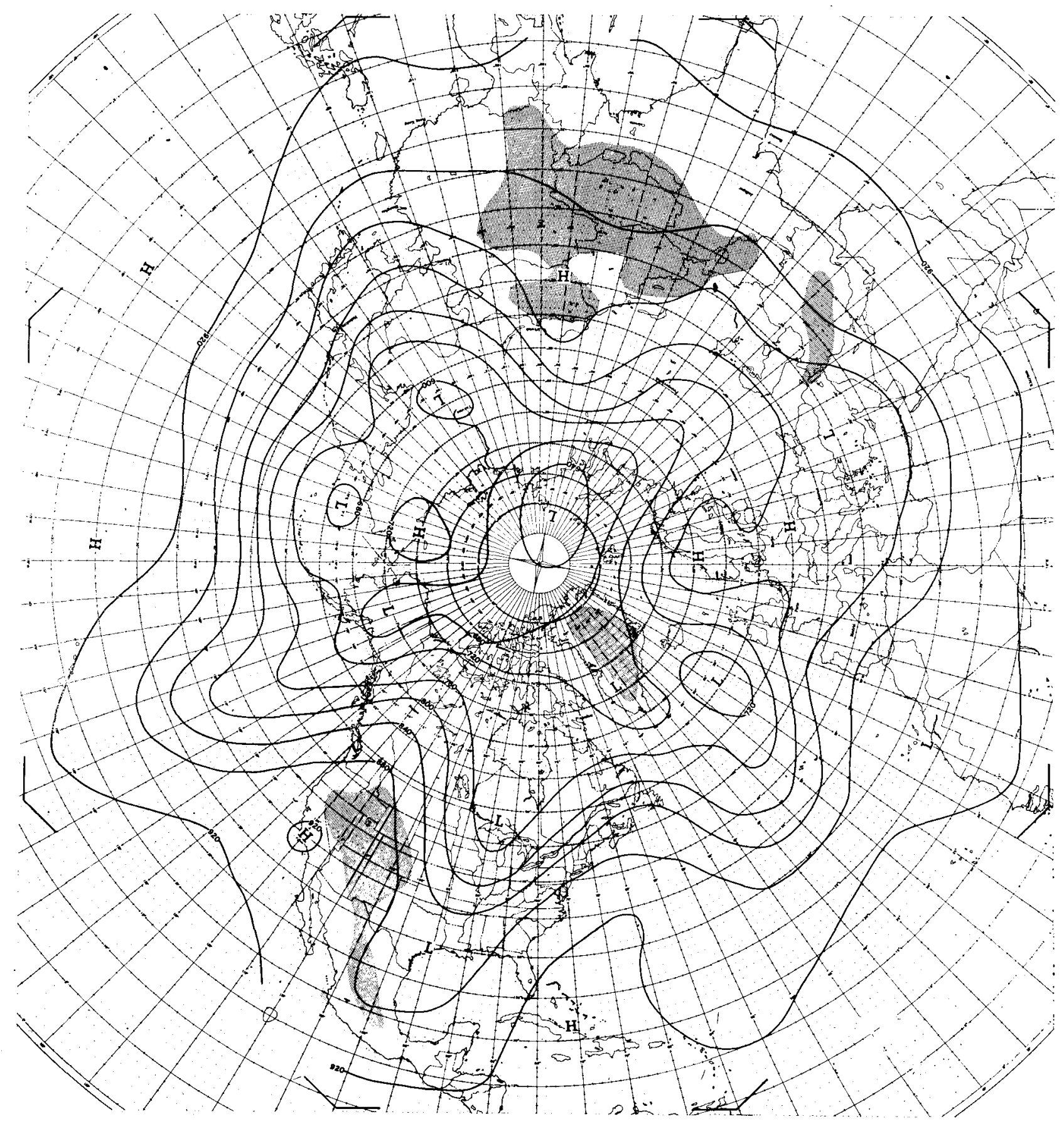

FIGURE 8.-Verifying 500-mb. chart, 1200 GMT, April 4, 1960, for forecast made from figure 7.

from the southwest over southeastern Asia and Japan by $48 \mathrm{hr}$. (particularly if one adds mentally the initial zonal flow) is suggestive of the well known jet stream observed to form in that region. $\Lambda \mathrm{J}_{\mathrm{s} o}$, the ridge appearing over the Rocky Mountains with the flow from the north on the east side of the mountains resembles the perturbations on the normal charts.

\section{FORECASTS WITH METEOROLOGICAL DATA}

A series of forecasts was made using initial data from ten different days, four from April 1960, and the remaining selected at random. From each set of initial data, two 48-hr. forecasts were made-one with mountain and friction effects excluded and one with these effects included. Verifications of $500-\mathrm{mb}$. geostrophic winds and heights were made over a restricted area of North America (inside dashed line in fig. 7). A verification over the Asian area would have been desirable but was not attempted because of the inadequate data over the Asian Plateau. The verifications are presented in table 2 . 


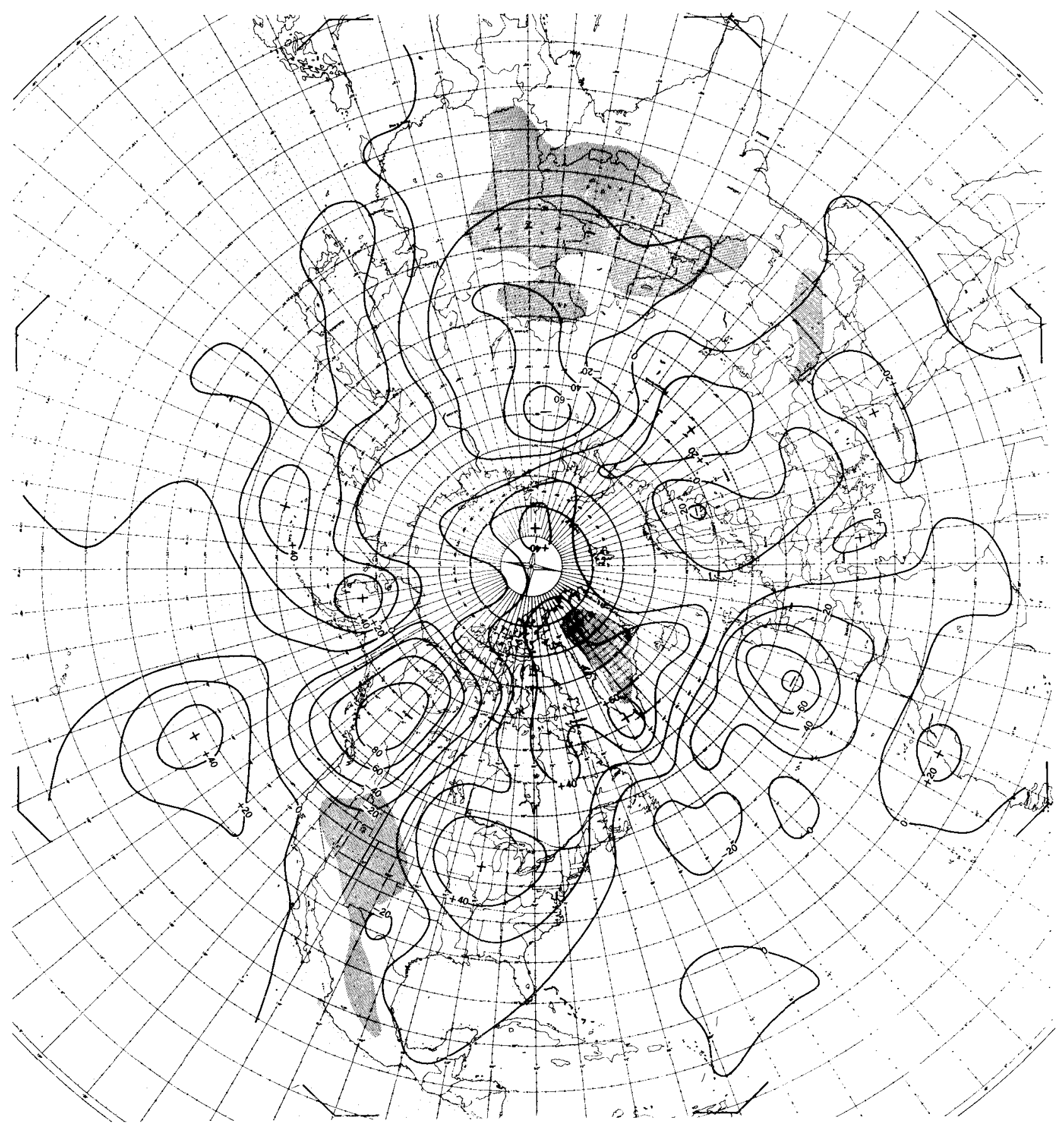

Figune 9.--Error (in decafeet) of 48-hr. barotropic forecust from 1200 ciut, April 2, 1960, 500 mb., with no mountain or friction effects included in model.

These verifications show a general trend toward inprovement of the forecasts when mountain and friction effects are included in the forecast model. In considering the modest amount of error reduction, we should remember that, according to the well-known rules of statisties, the effect on the total root-mean-square error of removal of one of several error sources of about equil importance is relatively slight. Also, due to the fact that the forecast model is simple (barotropic) and the surface winds are obtained by a guess, the friction and mountain effects computed in these forecasts represent only an approximation to the actual atmospheric processes.

\begin{tabular}{|c|c|c|c|c|c|c|c|c|}
\hline \multirow{2}{*}{ dato } & \multirow{2}{*}{$\begin{array}{l}\text { Time } \\
\text { (GiMT) }\end{array}$} & \multirow{2}{*}{$\begin{array}{l}\text { Total } \\
\text { windel }\end{array}$} & \multicolumn{3}{|c|}{$\begin{array}{l}\text { Root-mean-square er- } \\
\text { rors of wind forecasts } \\
\text { (knots) }\end{array}$} & \multicolumn{3}{|c|}{$\begin{array}{l}\text { Root-mean-square er } \\
\text { rors of height forecast } \\
\text { (fect) }\end{array}$} \\
\hline & & & $\begin{array}{l}\text { Persist- } \\
\text { ence } \\
\text { lore- } \\
\text { casl. }\end{array}$ & $\begin{array}{c}\text { No } \\
\text { mitns. } \\
\text { or fric- } \\
\text { tion }\end{array}$ & $\begin{array}{l}\text { Mitns. } \\
\text { and } \\
\text { frie- } \\
\text { tion }\end{array}$ & $\begin{array}{l}\text { Persist- } \\
\text { ence } \\
\text { fore- } \\
\text { cast }\end{array}$ & $\begin{array}{c}\text { xo } \\
\text { mtns. } \\
\text { or fric- } \\
\text { tion }\end{array}$ & $\begin{array}{l}\text { Mitns. } \\
\text { and } \\
\text { frie- } \\
\text { tion }\end{array}$ \\
\hline July 15,19 & 100 & 21.9 & 17.0 & 14.8 & 14.0 & & 199 & 189 \\
\hline & 00 & 24 & & 15.2 & & & $\begin{array}{l}159 \\
154\end{array}$ & 134 \\
\hline $\mathrm{J}$ & 00 & 54 & 3 & 23.2 & 24 & 324 & 267 & 247 \\
\hline a & 00 & 3 & $4 !$ & 30 & 31 & 394 & 333 & 304 \\
\hline Jan. 3 & 00 & 37 & 3 & 32 & 34 & 407 & 476 & 514 \\
\hline Feb. 14,19 & 00 & & & & & & 332 & 271 \\
\hline Apr. 2, 196 & 12 & 39 & & 26. & & & 330 & $\begin{array}{l}264 \\
215 \\
215\end{array}$ \\
\hline A pr, 21,19 & 00 & 34 & 49 & 38.6 & 35 & $\begin{array}{l}323 \\
649\end{array}$ & 470 & $\begin{array}{l}21.5 \\
442\end{array}$ \\
\hline A pr. 23,1960 & 00 & 31.7 & 34.3 & 23.8 & 20.4 & 399 & 253 & 267 \\
\hline Metan .. & & 35.7 & 31.1 & 25.3 & 24.1 & 354 & 311 & 285 \\
\hline
\end{tabular}




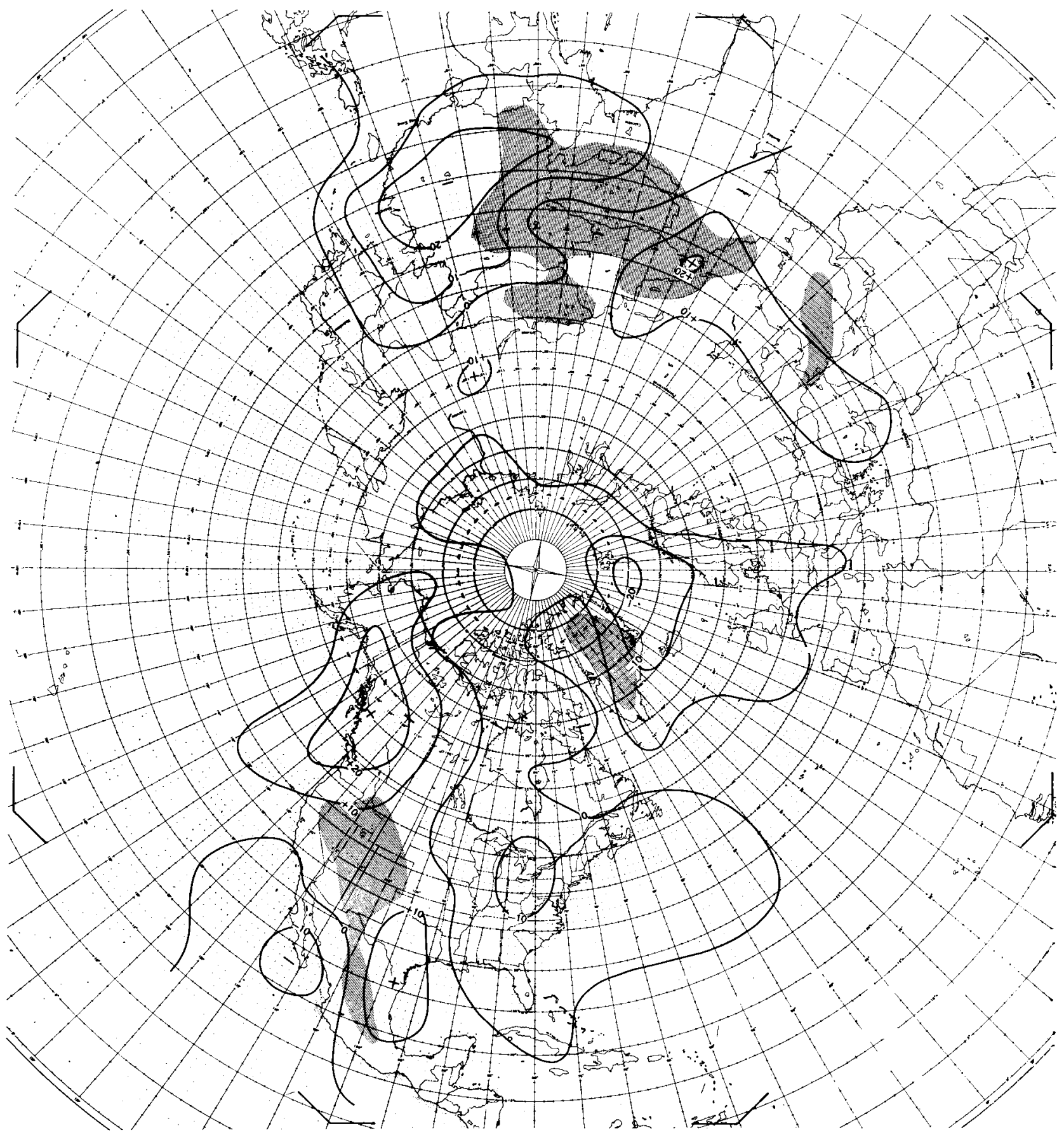

Figure 10.-Contribution of mountains and friction to 48-hr. forecast from 1200 GMT, April 2, 1960, obtained by subtracting 48-hr. forecast made without mountain and friction effects from 48 -hr. forecast made with both effects. (Labeled in decafeet.)

In order to see some of the results in greater detail, let us consider two examples. In one of these, the Rocky Mountain area was dominated by a ridge. In the other, it was dominated by a trough. Furthermore, the height verifications (table 2 ) showed an improvement in one case and a deterioration in the other as a result of the inclusion of terrain effects.

The first of these, April 2-4, 1960, figures 7 and 8, shows the intensification of a $500-\mathrm{mb}$. ridge over the Rocky Mountains. The errors of the 48-hr. forecast made with- out terrain effects, figure 9, are unusually large for barotropic forecasts at this time of the year, indicating that practically none of the ridge development was forecast. The added forecast change from the terrain effects, figure 10 , shows the reduction of error in the mountainous area of western Canada by about 25 percent of the total error. In investigating this case lurther, it was discovered that the surface wind approximation used in the model gave a surface (gradient level) wind of only half the observed va'ue at the initial time. If the surface wind approxima- 


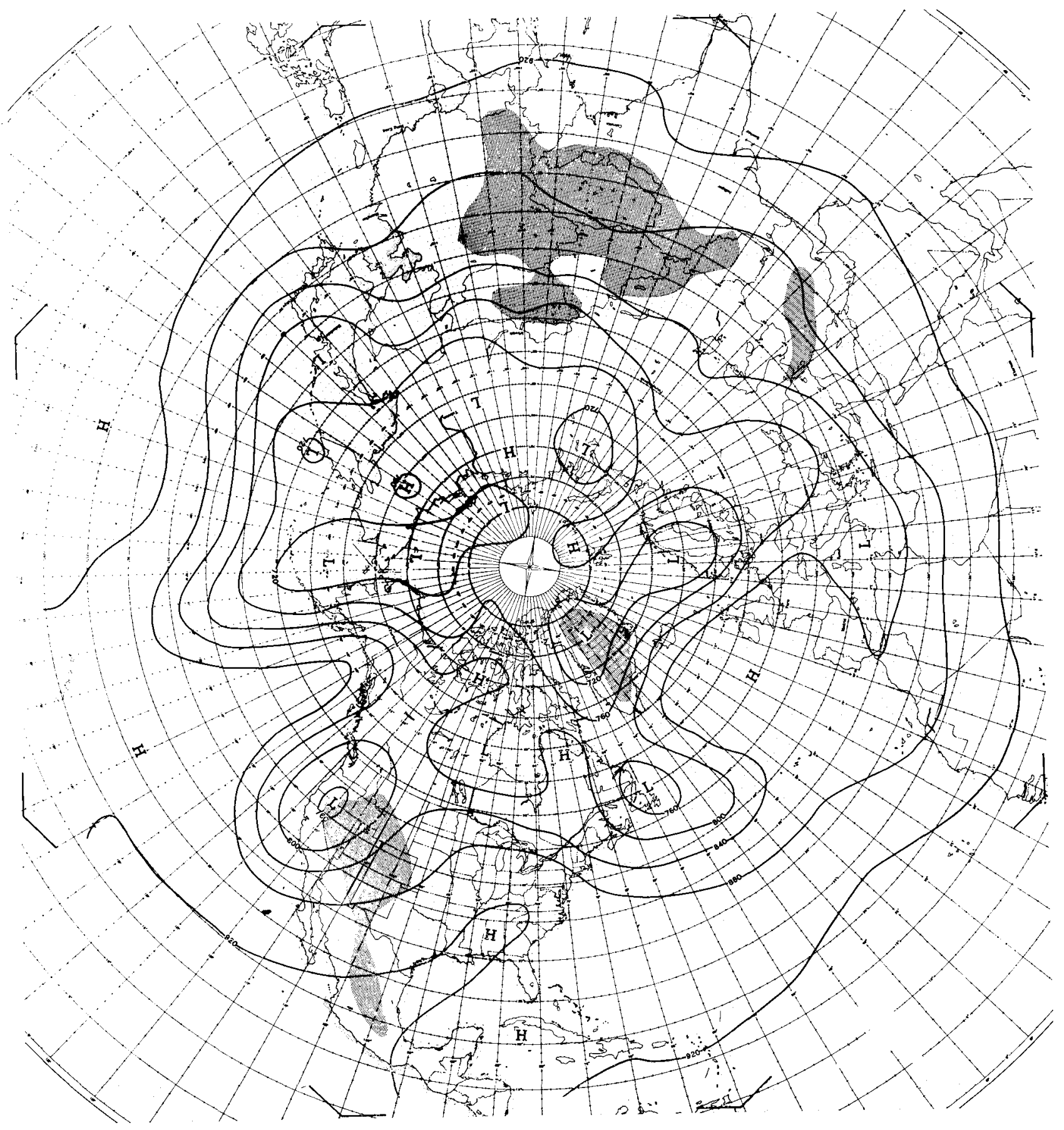

Fraure 11. -Initial 500-mb). chart for 0000 смт, April 23, 1960.

tion had been accurate, over hall of the large crrors over North Anerica would have been removed in this rase.

The attempted correction of non-existent crrors over China in this case illustrates a special problem. The objective analysis program (Cressman [5]) uses as a first guess the $12-\mathrm{hr}$. forecast from the previous observation time. This is made at present from a foremst model having only an ineffective mountain term and no friction. It tends to forecast too strong winds over the Asian Plateau, as shown by an occasional late report received from Tibet. As a result, the forecast-analysis system tends to perpetuate this type of error in this area. Thus when an analysis made by this system is used as initial data for a forecast with realistic mountain and friction effects, too strong terrain corrections are obtained. We should expect that when a feedback from a mountainfriction forecast model is made into the analysis system improved analyses showing weaker winds over the Asian Plateau will result.

In the second example, April 23-25, 1960, the Rocky 


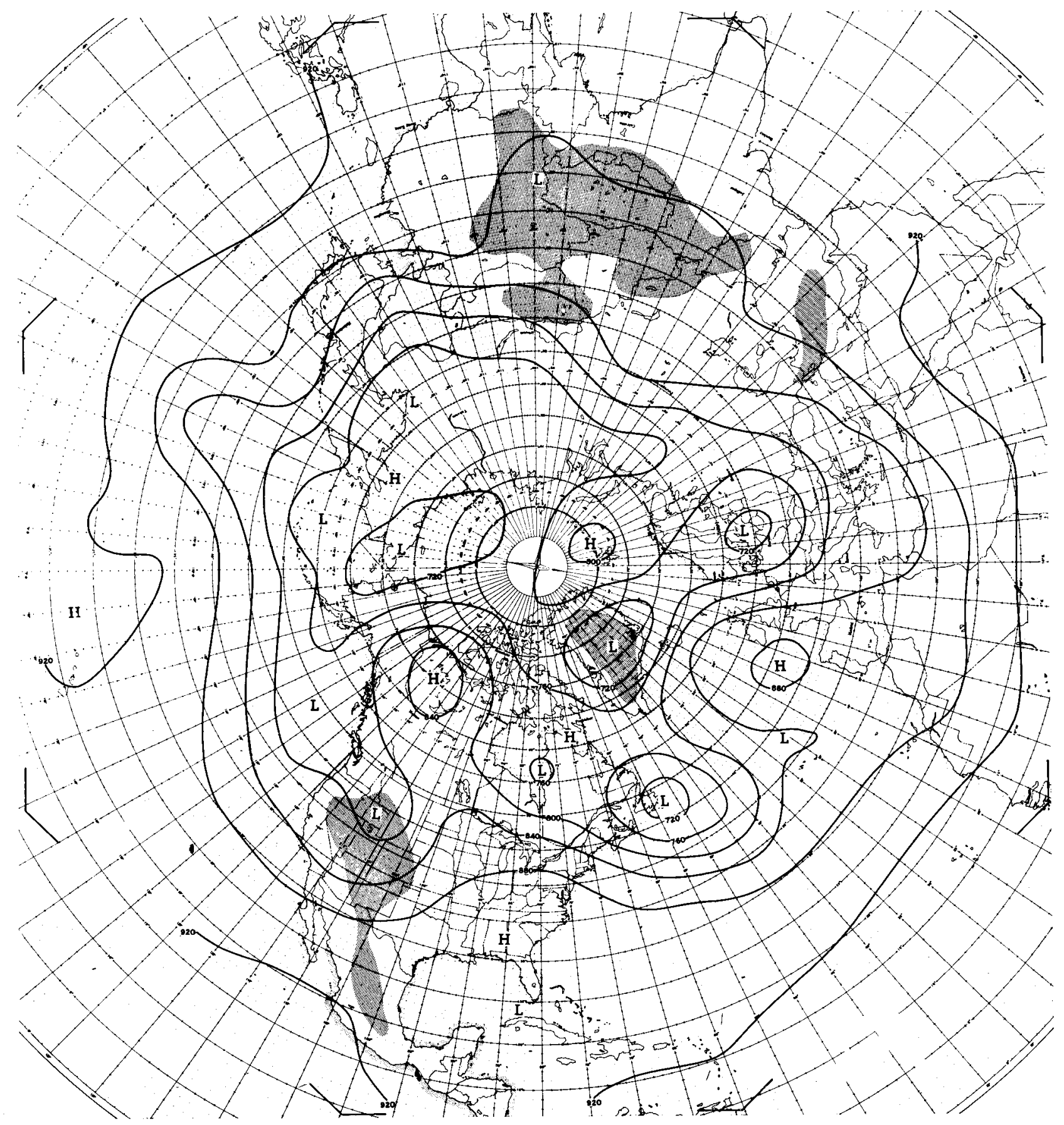

Figure 12.-Verifying 500-mb. chart, 0000 aмT, April 25, 1960, for forecast made from figure 11.

Mountain area was dominated by cyclonic flow. The Low in the western States at the initial time (fig. 11) moved slowly northeastward with filling (fig. 12). The failure of the forecast without terrain effects to forecast the filling is shown by the error chart of figure 13 . 'The contribution of mountains and friction, shown in figure 14, produced a height change in the forecast very nearly equal and opposite to the large error appearing in figure 13 . The fact that the root-mean-square height error of the forecast was slightly increased by the inclusion of the terrain effects runs contrary to expectations from looking at the maps, and reflects the treacherous nature of uninterpreted root-mean-square errors. Despite the verification, one obtains an impression of a substantial improvement gained by incorporating the terrain effects.

\section{CONCLUSIONS}

From the above study we conclude that combined mountain and friction effects in the atmosphere are responsible for large and recurrent forecast errors. The action of terrain on the atmosphere is probably of equal 


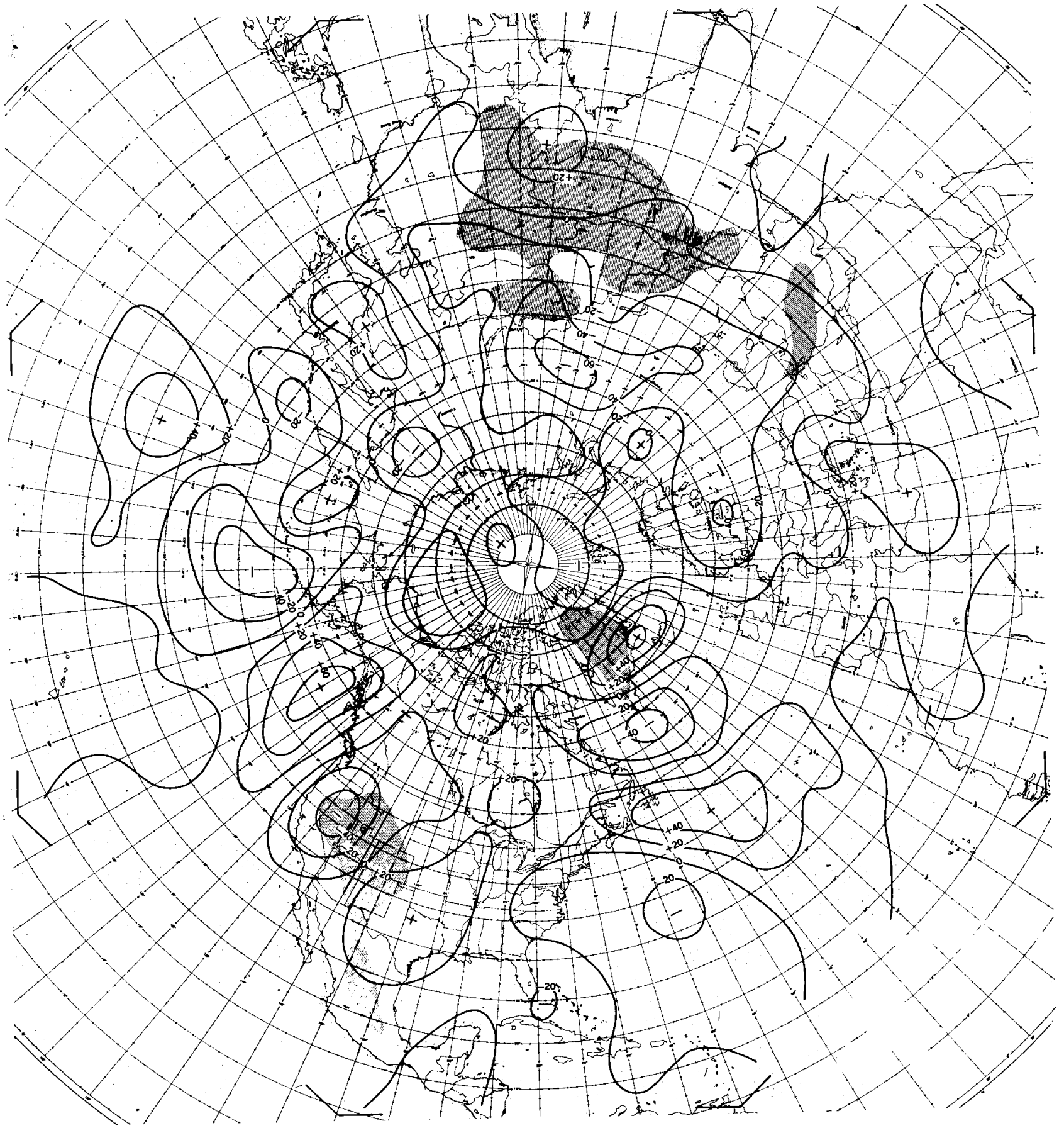

FIGURE 13.--Error (in decafeet) of 48-hr. barotropic forecast from $0000 \mathrm{GMT}$, April 23, 1960, with no mountain or friction effects included in forecast model.

importance with cyclogenesis in producing errors in the current barotropic forecast model. The principal barrier to removing a large part of these errors is the lack of an accurate surface wind.

The inclusion of mountain and surface friction in more advanced forecast models appears to be absolutely necessary. If this is not done, serious forecast errors will exist through a deep layer of the atmosphere.

\section{ACKNOWLEDGMENTS}

The writer takes this opportunity to thank Capt. Mirco P. Snidero, U.S.A.F., JNWP Unit, who coded and checked out the entire program for the IBM 704.

\section{REFERENCES}

1. V. L. Arkhangelskii, "O Vysote Urovnâ, Treniâa v Usloviı̂akh 


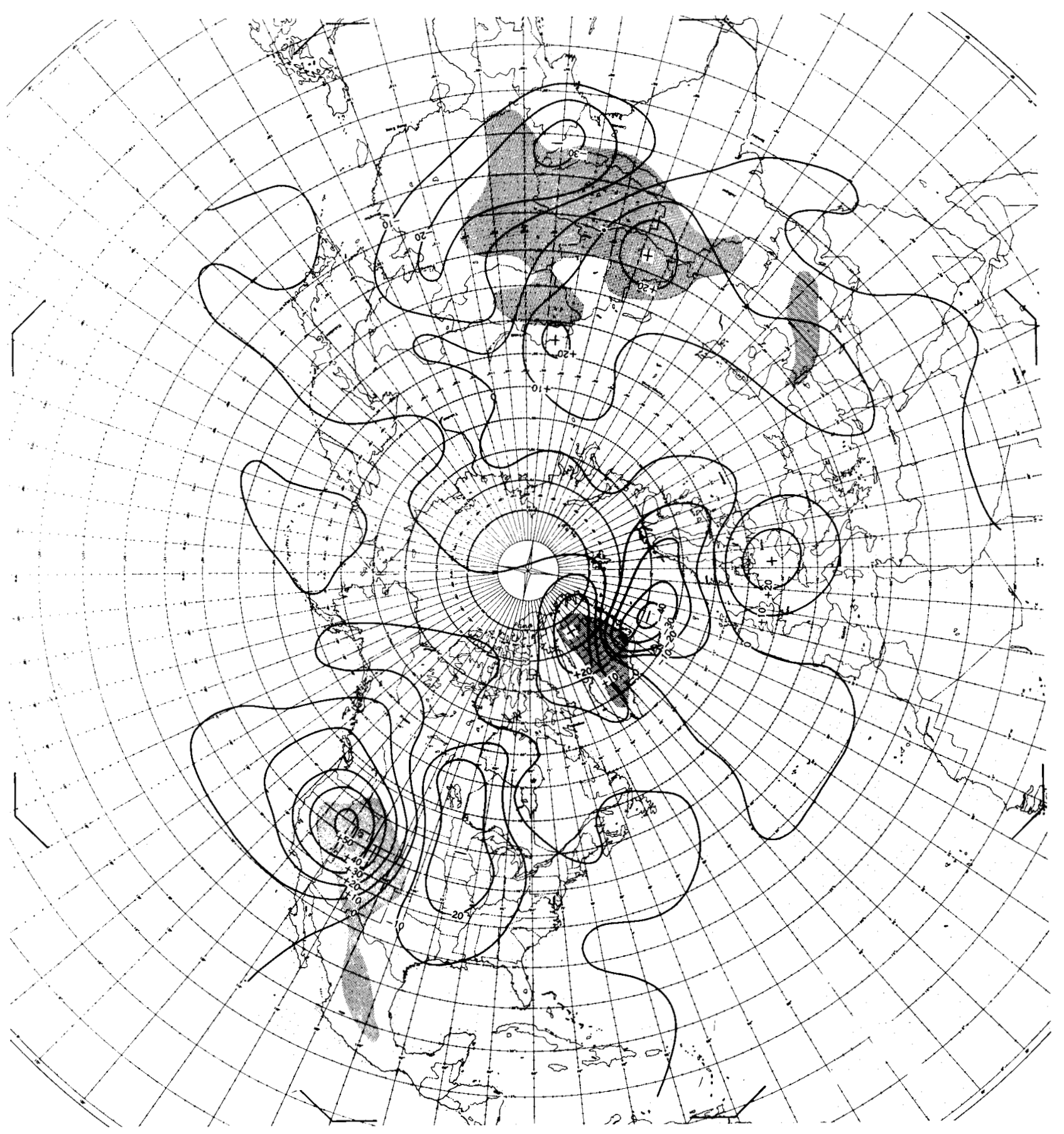

FIgURE 14. Contribution of mountains and friction to 48-hr. forecast from $0000 \mathrm{GMT}$, April 23, 1960, obtained by subtracting 48-hr. forecast made without mountain and friction effects from 48 -hr. forecast made with both effects. (Labeled in decafeet.)

Srednegornogo Rel'efa," (On the Depth of the Friction Layer under Conditions of Moderately High Mountains,) Meteorologita $i$ Gidrologiza No. 2, March-April, 1955, pp. 27-28.

2. A. Baumgartner, "Untersuchungen über den Wärme- und Wasserhaushalt eines jungen Waldes," Berichten des Deutschen Wetterdienstes, vol. 5, No. 28, 1956, pp. 3-53.

3. L. Berkofsky and E. A. Bertoni, "Mean Topographic Charts for the Entire Earth," Bulletin of the American Meteorological Society, vol. 36, No. 7, Sept. 1955, pp. 350-354.
4. G. P. Cressman, "Barotropic Divergence and Very Long Atmospheric Waves," Monthly Weather Review, vol. 86, No. 8, Aug. 1958, pp. 293-297.

5. G. P. Cressman, "An Operational Objective Analysis System," Monthly Weather Review, vol. 87, No. 10, Oct. 1959, pp. $367-374$.

6. M. H. Halstead, R. L. Richman, W. Covey, and J. D. Merryman, "A Preliminary Report on the Design of a Computer for Micrometeorology," Journal of Meteorology, vol. 14, No. 4, Aug. 1957, pp. 308-325. 
7. J. Holmboe, G. E. Forsythe, and W. Gustin, Dynamic Meleorology, Wiley and Sons, New York, 1945, (see p. 240.)

8. H. H. Lettau, "A Re-examination of the 'Leipzig Wind Profile' Considering Some Relations between Wind and Turbulence in the Frictional Layer," Tellus, vol. 2, No. 2, May 1950, pp. 125-129.

9. H. H. Lettau, "Summary of Non-Dimensional Characteristics of Boundary Layer Theory," pp. 337-372 in Exploring the Atmosphere's First Mile, H. H. Lettau and B. Davidson (Editors), vol. 1, Pergamon Press, New York, 1957.

10. H. H. Lettau, "Wind Profile, Surface Stress, and Geostrophic Drag Coefficients in the Atmospheric Surface Layer," $A d$ vances in Geophysics, vol. 6, 1959, pp. 241-257.

11. Y. Mintz, "An Empirical Determination of Surface Drag Coefficients for Extended-Range and Long-Range Numerical Weather Forecasting and the Study of the Generai Circulation," Article X in Large Scale Synoptic Processes, Dept. of Meteorology, University of California at Los Angeles, June 1957.

12. Y. Mintz, "Design of Some General Circulation Experiments," The Bulletin of the Research Council of Israel, Section G-Geo. Sciences, vol. 7G, No. 2-3, Oct. 1958, pp. 67-113.

13. E. Palmén, "On the Mean Meridional Circulation in Low Latitudes of the Northern Hemisphere in Winter and the Associated Meridional and Vertical Flux of Angular Momentum," Article VII in Investigations of the General Circulation of the Atmosphere, Dept. of Meteorology, University of California at Los Angeles, Mareh 1955.

14. J. S. Sawyer, "The Introduction of the Effects of Topography into Methods of Numerical Forecasting," Quarterly Journal of the Royal Meteorological Society, vol. 85, No. 363, Jan. 1959, pp. 31-43.

15. R. S. Scorer, "Theory of Waves in the Lee of Mountains," Ouarterly Journal of the Royal Meteorslogical Society, vol. 75, No. 374, Jan, 1949, pp. 41-56.

16. W. Seeliger, "Höhenwind und Gradientwind," Beiträge zur Physik der freien Atmosphäre, vol. 24, 1938, pp. 130-148.

17. P. A. Sheppard, H. Charnock, and J. R. D. Francis, "Observations of the Westerlies over the Sea," Quarterly Journal of the Royal Meteorological Society, vol. 78, No. 338, Oct. 1952, pp. $563-582$.

18. P. A. Sheppard and M. H. Omar, "The Wind Stress over the Ocean from Observations in the Trades," Quarterly Journal of the Royal Meteorological Society, vol. 78, No. 338, Oct. 1952 , pp. $583-589$

19. V. P. Starr and R. M. White, "A Hemispherical Study of the Atmospheric Angular-Momentum Balance," Quarterly Journal of the Royal Meteorological Society, vol. 77, No. 332, Apr. 1951, pp. 215-225.

20. R. C. Sutcliffe, "Surface Resistance in Atmospheric Flow," Quarterly Journal of the Royal Meteorological Society, vol. 62, No. 263, Jan. 1936, pp. 3-12.

21. H. U. Sverdrup, "The Stress of the Wind on the Ice of the Polar Sea," Skrifter Norsk Polarinstitult, No. 111, 1957, 11 pp.

22. G. I. Taylor, "On Eddy Motion in the Atmosphere," Philosophical Transactions, Royal Society of London, vol. 215, A, 1914, pp. $1-26$.

23. A. Wiin-Nielsen, "On Certain Integral Constraints for the TimeIntegration of Baroclinic Models," Tellus, vol. 11, No. 1, Feb. 1959, pp. 45-59. 